\title{
The Social Media Response From Athletes and Sport Organizations to COVID-19: An Altruistic Tone
}

\section{Stirling Sharpe and Charles Mountifield University of Canberra}

\author{
Kevin Filo \\ Griffith University
}

\begin{abstract}
The global coronavirus (COVID-19) pandemic has resulted in restrictions on gatherings of large crowds, the suspension of live sport events across the globe, and the relegation of topical televised sport to broadcasts of past events and competitions. Consequently, there has been a shift in focus from the entertainment aspect of sport to the health and well-being aspects of sport. As athletes, teams, and sport organizations have become subject to government legislation concerning physical distancing, self-isolation, and lockdowns, the resultant spare time has presented the opportunity for individual athletes and sport organizations to pursue an approach to social media that includes viral challenges, fundraising, and socializing online. This paper provides a commentary on select high-profile athletes' and sport organizations' social media behavior during the COVID-19 pandemic, which has adopted an altruistic tone.
\end{abstract}

Keywords: altruism, fan engagement, fundraising, health, social responsibility

Save for the world wars in the 20th century, the impact of coronavirus (COVID-19) on global affairs is unprecedented. Its effect has been felt in all areas of human endeavor, which includes a pronounced impact on the world of sport. The Tokyo Olympic Games, originally scheduled for July and August 2020, were postponed for the first time in modern history. Across the globe, sport of every kind, from grassroots community sport to the professional levels, has been cancelled or rescheduled. This has not, however, deterred sport organizations, teams, and athletes from connecting with fans. Much of this engagement has been through social media, which has had a significant influence on the connection between sport brands, including high-profile athletes, and their fans. As part of this connection, public campaigns, including advocating the need for better health awareness and hygiene practices, have influenced some of the messages conveyed by athletes to their fans.

This article provides a short opinion-based commentary principally informed by observations of the authors obtained through social media usage and news 
reporting. This commentary commences with a brief review of social media literature to establish grounds for the claim that a shift is occurring in how sport organizations and athletes alike are using social media. Next, the article provides several examples of altruistic social media posts organized into three categories. Finally, there is a discussion and future research direction section, followed by a conclusion to the commentary.

\section{Social Media and Sport}

Williams and Chinn (2010) stated that social media is composed of the "tools, platforms, and applications that enable consumers to connect, communicate, and collaborate with others" (p. 422). Social media is a unique form of communication that transcends geographic and social borders via instantaneous information communication (Filo, Lock, \& Karg, 2015; Perloff, 2010). Filo et al. (2015) included user cocreation in their definition, while also highlighting the relationship between consumers and organizations or athletes. Moreover, there is the prospect of improving the relationship between consumers and organizations through the effective use of social-media-facilitated two-way communication (Campos, Anagnostopoulos, \& Chadwick, 2013). Indeed, these mediums have transformed how consumers and businesses interact with each other so much that Abeza, O'Reilly, and Reid (2013) labeled consumers as both "producers" and "distributors" of information (p. 123). Meraz (2009) pointed out that social media are "architected by design to readily support participation, peer-to-peer conversation, collaboration, and community" (p. 682). To this end, social media are being embraced by consumers to form part of their communication mix (Abeza et al., 2013; Mangold \& Faulds, 2009) that extends to interacting with their favorite athletes, teams, and sport brands, as well as other fans (Stavros, Meng, Westberg, \& Farrelly, 2014; Williams \& Chinn, 2010).

Athletes, teams, and sport organizations have been using social media as part of their public relations and communication efforts (Filo et al., 2015; Pegoraro, 2010). Athletes have been encouraged to adopt a more active approach in their public presentation via social media (e.g., Lebel \& Danylchuk, 2012; Smith \& Sanderson, 2015) and to focus their "away from the game" presentation on authenticity (Smith \& Sanderson, 2015, p. 355). Sport marketing literature has also revealed that social media is aiding organizations and athletes in increasing fan identification (e.g., Meng, Stavros, \& Westberg, 2015; Williams, Chinn, \& Suleiman, 2014) and brand awareness (e.g., Na, Kunkel, \& Doyle, 2020; Pegoraro, Scott, \& Burch, 2017). Social media can create unique and powerful opportunities for high-profile athletes to capitalize on through increased athlete-fan interaction (Pegoraro, 2010) in a cost-effective manner (Filo et al., 2015). There is the potential for amplifying these opportunities further through proactive measures taken by sport organizations (Campos et al., 2013), opportunities that can translate to commercial gain. For example, the Australian Capital Territory Brumbies Super Rugby Club repost their athletes' social media activities to drive fans to the Brumbies' official social media accounts (Sharpe, Kunkel, Scott, \& Beaton, 2017). This represented a commercial consideration of the former media manager for the club who stated that "the difference between you having 200,000 followers on 
Facebook and 100,000 can be $\$ 100,000$. It's a huge business, ... and we are trying to sell ourselves all the time" (Scott, Beaton, Kunkel, \& Sharpe, 2017, p. 228).

In the context of the current COVID-19 pandemic, sport organizations should shift their focus to fostering long-term relationships with fans, while understanding that their needs, wants, and values have changed (Abeza et al., 2013; Bee \& Kahle, 2006). Social media, itself a rapidly evolving technological platform (Abeza, O’Reilly, Séguin, \& Nzindukiyimana, 2015), facilitates the opportunity for organizations and athletes to engage with their consumer base in an innovative and evolving manner. For athletes, however, the opportunities afforded by social media have seemingly taken on additional meaning. Across a range of sports, the social media responses from athletes impacted by COVID-19 are varied and are, prima facie, somewhat removed from commercial objectives. Instead, they appear to have a more altruistic intent-reflecting the human tendency to help others (Dougherty, 2017; Hoffman, 1981)—with the collective concerns of the public and fans in mind. To this end, the following sections provide categorization of the use of social media during the global COVID-19 pandemic by elite-level sport organizations and individual athletes.

\section{Observations}

This section outlines examples gathered through observations via the authors' social media use, as well as reports in news outlets of sport organizations, and athletes' social media responses to the COVID-19 pandemic. Sport organizations, teams, and owners have demonstrated a willingness to contribute positively to the COVID-19 pandemic, often through measures of financial goodwill and information dissemination. Meanwhile, individual athletes have displayed a range of social media activity, including fundraising and messages of support for National Health Services (NHSs) at the frontline of the battle against COVID-19. Of note is the effort some high-profile athletes put forth concerning health messaging and exercise promotion, social distancing, and good hygiene practices. The following examples, which are limited to those posted in the English language, are categorized into (a) social and civic responsibility messaging, (b) fundraising and physical activity challenges, and (c) financial generosity.

\section{Social and Civic Responsibility Messaging}

Several organizations and athletes have been employing social media during the COVID-19 pandemic to advocate for and encourage socially responsible behavior among their followers. The social and civic responsibility messaging category refers to organizations and athletes making posts that reinforce or champion the requests and requirements of medical professionals in response to the pandemic. These demands encourage every member of society to assist in reducing the spread of COVID-19 by practicing physical/social distancing and handwashing procedures. Further, social and civic responsibility messages may simply entail disseminating information or becoming involved directly while using their platform to champion messages in line with medical professionals. 
With over 200 million followers on Instagram and over 80 million followers on Twitter, Cristiano Ronaldo (@ Cristiano) shared pictures of himself teaching his children about handwashing. In rugby, former All Black Tabai Matson has been promoting the need for handwashing (@ Skysportnz, 2020). Kenyan long-distance runner and marathon world record holder Eliud Kipchoge has been promoting, via Twitter, health messages, including handwashing practices and social distancing protocols (@EliudKipchoge, 2020). Former 100M record holder Asafa Powell has been promoting improved hygiene practice in Jamaica (@officialasafa). Bellator women's featherweight champion Cris Cyborg has promoted the importance of handwashing through her Twitter posts (@criscyborg).

Philip Doyle, an Irish rower who originally put his medical career on hold to focus on his Olympic preparation, has now reversed that decision and will return to medicine. Doyle has posted pictures of himself in medical scrubs on his Instagram page (@ philipdoyle2), along with another photo of him standing in front of Daisy Hill Hospital in his uniform. Likewise, Welsh rugby player and qualified medical doctor, Jamie Roberts, has volunteered for the Cardiff and Vale University Health Board and posted several frontline experiences and health messages on his Twitter account (@Jamiehuwroberts).

The Australian Institute of Sport, the nation's peak high-performance sport organization, has established a dedicated COVID-19 web page with the intent of providing up-to-date information for the nation's sport governing bodies. The web page includes items such as mental health, well-being, funding assistance, and a collection of government advice on restrictions (Australian Institute of Sport, 2020). Canadian ice hockey star Hayley Wickenheiser, a four-time Olympian who works in player development for the Toronto Maple Leafs while juggling medical school, is working to disseminate information about COVID-19 directly to her 73,000 Twitter followers (@wick_22). In basketball, U.S. athlete Steph Curry has been urging fans to practice social distancing and has also been hosting online quizzes. Curry then teamed up with Dr. Anthony Fauci, the head of the U.S. National Institute of Allergy and Infectious Diseases, for an interview on Instagram to discuss the impact of COVID-19 and the steps the public can take to stay safe (Curry, 2020). The NBA Together, a social engagement campaign involving a variety of professional players, has been launched to "share the latest health and safety information and use digital tools and virtual events to help keep communities connected during this time of social distancing" (National Basketball Association, 2020, para. 2).

Collectively, the examples listed above demonstrate that athletes and sport organizations are utilizing the tools afforded by social media to educate their followers about how individuals can do their part to stop the spread of COVID-19. This education has occurred via demonstrations, interviews, and active involvement in the response. This category is particularly notable as most of the messaging and initiatives assume no relation to an athlete's physical ability or a sport organization's professional competency.

\section{Fundraising and Physical Activity Challenges}

The fundraising and physical activity challenges category highlights how organizations and athletes have participated in, or instigated, challenges through social media to raise funds for a charitable cause or to inspire their followers and 
communities to be physically active during periods of isolation. Former Welsh rugby captain Ryan Jones completed a charity garden marathon-he ran the full twenty-six miles in his back garden-not only to raise money for the NHS but also to encourage his followers to stay active (Jones, 2020). Similar to Jones's efforts, Scottish javelin record holder James Campbell completed a garden marathon, raising over $£ 29,000$ for the NHS and inspiring similar efforts from the public (Campbell, 2020).

Soccer stars like Lionel Messi and Marcus Rashford participated in and promoted the \#StayAtHomeChallenge. Based on people videoing themselves doing as many "keepy-ups" as possible with a roll of toilet paper, the challenge encouraged people to challenge friends, resulting in an abundance of activity on social media. Zlatan Ibrahimović is promoting exercise with the "Kick the Virus Away" campaign through a GoFundMe page (@GoFundMe, 2020). On April 2, 2020, the International Hockey Federation launched a campaign titled \#Stay HomeStayStrong designed to "keep our wonderful hockey community united and focused on what we all need to do to stay fit, healthy and protect others" (International Hockey Federation, 2020). The International Hockey Federation campaign was launched by Team Great Britain athlete Sam Ward, who has been posting \#IsolationOlympics videos on his platforms.

In Canberra, Australia, players from the Australian Capital Territory Brumbies (Super Rugby) and Canberra Capitals (Women's National Basketball League) have taken to social media and joined in the Canberra Hospital Foundation's Paediatric Easter Juggling Challenge (Bertoldo, 2020). These online initiatives were positioned as ways to overcome the fact that representatives from each club are not able to visit the hospital due to social distancing restrictions. As with other sports, golfers are adopting different approaches to keep themselves and their fans entertained and active. Former world No. 1 golfer Brooks Koepka (@BKoepka) has been encouraging physical exercise by promoting indoor golf activities to the public.

In the United Kingdom, the Team Great Britain gymnastics team has been promoting an indoor high-intensity interval training workout to the public. Olympian Katarina Johnson-Thompson (@JohnsonThompson) shared a video of an at-home heptathlon she completed. Athlete Jaide Stepter (@Jaidesteps) shared a video of a \#SistaCircuit, whereby her sister formed part of a cardio and core circuit. Hockey Australia has engaged national team athletes to post several videos explaining and demonstrating skill-based drills that can be performed at home. Hockey Australia has also engaged national team strength and conditioning, health and well-being, and nutrition staff to create instructional videos for all hockey fans. These examples illustrate how, amidst the COVID-19 pandemic, athletes and sport organizations have utilized social media to initiate a collection of challenges to encourage their followers to make financial contributions to the crisis and/or to remain physically active despite social distancing measures. These initiatives often align with sport or the specific sport in which the athlete or team is involved, but remain broadly focused on employing social media to promote a positive and healthy response to the pandemic.

\section{Financial Generosity}

The category of financial generosity reflects social media posts from athletes and sport organizations that demonstrate direct contributions in response to the 
COVID-19 pandemic. In soccer, Chelsea Football Club has offered NHS staff temporary accommodations at the club's Millennium Hotel to help in the fight against COVID-19 (Harvey, 2020). This offer was replicated by Manchester United legends Ryan Giggs and Gary Neville, who have offered their hotels as temporary accommodations for NHS workers (Harvey, 2020). Both of these generous offers have been promoted on Twitter by @ChelseaFC and @ hotelfootballuk. Tweets and retweets of supportive initiatives to assist health care workers staying at the hotel, from both the public and the hotel, have dominated The Hotel Football UK Twitter page. In a similarly altruistic fashion, hotel co-owner and billionaire Peter Lim covered the cost of \$1million worth of meals for hospital staff in Singapore (@ hotelfootballuk, 2020).

In the United States, NBA franchises and players were some of the first to use social media to announce financial contributions to nonplaying staff. They have taken an altruistic approach to the outbreak through monetary contributions for nonplaying staff (Harvey, 2020). Major League Baseball donated U.S.\$1 million to the charity Feeding America, a move publicized on social media (@MLB, 2020). England World Cup cricketer Jos Buttler raised £65,100 by auctioning his World Cup playing shirt, with the funds going to the Royal Brompton \& Harefield Hospitals Charity. Buttler promoted this auction through many tweets, the initial one receiving more than 15,600 likes and 2,600 retweets (@josbuttler, 2020). In tennis, Australia's Nick Kyrgios made a generous offer on Instagram, saying he did not want anyone sleeping on an empty stomach. He asked followers to send him a private message if they needed some food, and he would personally deliver it to their door (Dutton, 2020). Similarly, British world boxing champion Amir Khan has promoted the work of his charitable foundation, which is distributing food and drinks to people in need (@amirkingkhan, 2020). The instances outlined above demonstrate the successful application of social media as a tool to announce donations and contributions made to those impacted by the pandemic.

\section{Discussion and Future Research Direction}

The examples provided in this article reveal that the use of social media by sport organizations and athletes has, for many, evolved in response to the impact of COVID-19. This change is illustrated by evidence that, during the COVID-19 pandemic, social media content has been driven by altruism, with little to no focus on the commercial aspects of sport. Of course, one could argue that there is likely to be a positive brand association derived from the altruistic posts highlighted above that can translate to longer-term commercial benefits. The position adopted in this article is that these unprecedented times have provided athletes and sport organizations with a unique opportunity to create and share content that is more focused on demonstrating and promoting altruism. Notably, athletes and organizations are engaging with the public on topics and issues not directly related to their sporting capabilities and competencies.

The social and civic responsibility advocates have put aside, or leveraged, their sporting pursuits to highlight health messages and promote behavioral changes that will assist in a global defense against COVID-19. The fundraising 
and physical activity challenges have actively encouraged their followers and the general community to remain active, while also creating fundraising initiatives to support individuals and communities impacted by the pandemic. Collated via hashtags such as \#StayAtHomeChallenge, there have been challenges to take part in viral activities or innovate home-based workouts and skill development. The examples of financial generosity, as promoted through social media, showcase altruism among sport organizations and athletes as they try to monetarily assist the less fortunate and those directly impacted by the pandemic. In all these cases, social media has been capitalized on for the opportunities it provides athletes and organizations to interact with their followers and communities. The tone of the content, we purport, can be attributed to an altruistic motivation (Dougherty, 2017; Hoffman, 1981) that transcends the usual commercial orientation of public relations and marketing efforts initiated via social media. In this sense, there is a recognition that the priorities of consumers and, indeed, athletes and sport organizations, have changed in response to the pandemic. As outlined by Abeza et al. (2013), it is vital that organizations and athletes recognize changing needs, wants, and values of their fans to establish and maintain long-term relationships.

While this article's foci are on sport organizations and athletes, it would be remiss to not comment on the consumer response. It was our observation that followers of sport organizations and athletes have responded positively to the aforementioned examples on social media. In some cases, fans have been able to interact with and pursue their sporting interests on a more personal level. To this end, health messages have been "liked" and retweeted through Twitter. Fundraising campaigns have received tremendous financial and moral support. Consumers have participated in viral challenges and competitions. Athletes have presented a different aspect of their "away from the game" selves (Smith \& Sanderson, 2015, p. 355), emerging with a sense of authenticity attached to the messages they have delivered. Of course, consumers are potentially missing the more customary social media content from athletes, leagues, and organizations. During the COVID-19 pandemic, however, the content appears to have engaged consumers in a manner that may become a more common expectation.

As sport organizations work hard to construct plans and timelines for the return of competition, it is likely that the production and delivery of these competitions will be significantly different. This may involve not allowing fans to attend or placing significant limitations on the number of fans who can attend, temperature testing, ticket price restructuring, and modified season format and timing, among other potential changes. With these changes in mind, fans will need to remain engaged. In these challenging times, many organizations and athletes may be placing increased emphasis on their social media activities in recognition that these are the primary means to connect with their fans in the absence of competition. To this end, opportunities exist for further academic research on athlete and social media usage in the context of COVID-19. This can include investigations of consumer responses, as well as consumer expectations moving forward. In addition, longitudinal work examining athlete and sport organization response and strategy while society's response and responsibilities evolve could make a contribution. 


\section{Conclusion}

The COVID-19 pandemic brings with it a collective responsibility to adhere to government guidelines and provisions. Athletes, teams, and sport organizations have embraced some of the challenges inherent to the situation and put human health and safety ahead of revenue. From the sport consumer's perspective, an opportunity exists to engage with their sporting interests through social media commentary, media cocreation, following the advice shared by athletes and teams, engagement with challenges, and fundraising contributions. This article has provided a collection of examples that illustrate an altruistic tone from athletes and sport organizations on social media in response to COVID-19. The examples provided demonstrate a level of concern for the well-being of communities. While it is not suggested that social media content focused on social responsibility and altruistic behavior commenced only in response to the COVID-19 pandemic, the crisis has provided an unprecedented and unique setting for athletes to display altruism via social media. In particular, messages on social media promoting hygiene, social distancing, and exercise provide a simple yet productive way for athletes and sport organizations to connect with sports fans and contribute to the global effort to slow the spread of COVID-19.

\section{References}

Abeza, G., O’Reilly, N., \& Reid, I. (2013). Relationship marketing and social media in sport. International Journal of Sport Communication, 6(2), 120-142. doi:10.1123/ijsc.6. 2.120

Abeza, G., O’Reilly, N., Séguin, B., \& Nzindukiyimana, O. (2015). Social media scholarship in sport management research: A critical review. Journal of Sport Management, 29(6), 601-618. doi:10.1123/JSM.2014-0296

Australian Institute of Sport. (2020, March). COVID-19 and sporting activity. Retrieved from https://ais.gov.au/health-wellbeing/covid-19

Bee, C.C., \& Kahle, L.R. (2006). Relationship marketing in sports: A functional approach. Sport Marketing Quarterly, 15(2), 102-110. doi:10.1.1.321.3472

Bertoldo, L. (2020, April 12). ACT Brumbies and Canberra capitals stars reach out to paediatric patients for Easter. The Canberra Times. Retrieved from https://www. canberratimes.com.au/story/6719916/canberra-athletes-juggle-for-easter-joy/

Buttler, J. [@josbuttler]. (2020, April 1). I'm going to be auctioning my World Cup Final shirt to raise funds for the Royal Brompton and Harefield Hospitals charity [Tweet; video detailing the auction embedded]. Twitter. Retrieved from https://twitter.com/ josbuttler/status/1245060033701916672

Campbell, J. (2020, April 1). James's running a marathon in my 6 metre long back garden. Just Giving. Retrieved from https://www.justgiving.com/fundraising/jamescampbell0104

Campos, C.J., Anagnostopoulos, C., \& Chadwick, S. (2013). Assessing the integration of Twitter into the strategic operations of sporting organisations. Sport Management International Journal, 9(1), 43-67. doi:10.4127/ch.2013.0076

Curry, S. [@StephenCurry30]. (2020, March 27). Thank you to everyone who tuned in earlier today on Instagram Live! I wanted to make sure everyone had access to the conversation on COVID-19 with Dr. Fauci [Tweet; link to YouTube recording of interview between Dr Fauci and Curry]. Twitter. Retrieved from https://twitter.com/ StephenCurry30/status/1243275443546886144 
Dougherty, T. (2017). Altruism and ambition in the dynamic moral life. Australasian Journal of Philosophy, 95(4), 716-729. doi:10.1080/00048402.2016.1256331

Dutton, C. (2020, April 6). Nick Kyrgios' touching message to people struggling in coronavirus fallout. The Canberra Times. Retrieved from https://www.canberratimes. com.au/story/6713692/nick-kyrgios-touching-message-to-help-in-coronavirus-fallout/

Filo, K., Lock, D., \& Karg, A. (2015). Sport and social media research: A review. Sport Management Review, 18(2), 166-181. doi:10.1016/j.smr.2014.11.001

GoFundMe [@GoFundMe]. (2020, March 19). Soccer star Zlatan Ibrahimovic (@Ibra_ official) has started a GoFundMe to support hospitals throughout Italy \& "kick the virus away" [Tweet; link to GoFundMe campaign]. Twitter. Retrieved from https://twitter. com/gofundme/status/1240333430291943429

Harvey, M. (2020, March 23). Sport solidarity: How sport responds to crisis-Lessons for COVID-19. Centre for Sport and Human Rights. Retrieved from https://www. sporthumanrights.org/en/resources/sport-solidarity-how-sport-responds-to-crisis-lessonsfor-covid-19

Hoffman, M.L. (1981). Is altruism part of human nature? Journal of Personality and Social Psychology, 40(1), 121-137. doi:10.1037/0022-3514.40.1.121

Hotel Football [@hotelfootballuk]. (2020, May 9). Our co-owner Peter Lim has this morning announced he will be funding $\$ 1$ million worth of meals for the frontline hospital staff in Singapore [Tweet; link to news article]. Twitter. Retrieved from https:// twitter.com/hotelfootballuk/status/1259050842507837440

International Hockey Federation. (2020, April 1). FIH launches 'Stay Home, Stay Strong' initiative. Retrieved from http://fih.ch/news/fih-launches-stay-home-stay-stronginitiative/?fbclid=IwAR01PvwvbOmrkbYPXCwSZ1 y0wLsI7hi09WsVircWuREmL Hziwu0Spwigu5o

Jones, R. (2020). Ryan's garden marathon. Just Giving. Retrieved from https://www. justgiving.com/fundraising/ryan-jones 72

Khan, A. [@amirkingkhan]. (2020, May 13). This week @ AKFoundation will distribute more food and drinks to those who need it the most in England [Tweet; link to foundation website]. Twitter. Retrieved from https://twitter.com/amirkingkhan/status/ 1260316013364744198

Kipchoge, E. [@EliudKipchoge]. (2020, March 20). To the people of Kenya and around the world let's be mindful of washing our hands and practice social distancing to help [Tweet; image with health messages and branding attached]. Twitter. Retrieved from https://twitter.com/EliudKipchoge/status/1240628291800891393

Lebel, K., \& Danylchuk, K. (2012). How tweet it is: A gendered analysis of professional tennis players' self-presentation on Twitter. International Journal of Sport Communication, 5(4), 461-480. doi:10.1123/ijsc.5.4.461

Major League Baseball [@ MLB]. (2020, March 17). [Tweet; Image with text, no caption]. Twitter. Retrieved from https://twitter.com/MLB/status/1239607834863718403

Mangold, W.G., \& Faulds, D.J. (2009). Social media: The new hybrid element of the promotion mix. Business Horizons, 52(4), 357-365. doi:10.1016/j.bushor.2009. 03.002

Meng, M.D., Stavros, C., \& Westberg, K. (2015). Engaging fans through social media: Implications for team identification. Sport, Business and Management, 5(3), 199-217. doi:10.1108/SBM-06-2013-0013

Meraz, S. (2009). Is there an elite hold? Traditional media to social media agenda setting influence in blog networks. Journal of Computer-Mediated Communication, 14(3), 682-707. doi:10.1111/j.1083-6101.2009.01458.x

Na, S., Kunkel, T., \& Doyle, J. (2020). Exploring athlete brand image development on social media: The role of signalling through source credibility. European Sport Management Quarterly, 20(1), 88-108. doi:10.1080/16184742.2019.1662465 
National Basketball Association. (2020). NBA together. NBA. Retrieved from https://cares. nba.com/nbatogether/

Pegoraro, A. (2010). Look who's talking-Athletes on Twitter: A case study. International Journal of Sport Communication, 3(4), 501-514. doi:10.1123/ijsc.3.4.501

Pegoraro, A., Scott, O., \& Burch, L.M. (2017). Strategic use of Facebook to build brand awareness: A case study of two national sport organizations. International Journal of Public Administration in the Digital Age, 4(1), 69-87. doi:10.4018/IJPADA. 2017010105

Perloff, R.M. (2010). The dynamics of persuasion: Communication and attitudes in the twenty-first century. New York, NY: Routledge.

Scott, O., Beaton, A., Kunkel, T., \& Sharpe, S. (2017). Media strategies to engage stakeholders and navigate crises: An interview with Paul Glover, media manager of the ACT brumbies super rugby franchise. International Journal of Sport Communication, 10(2), 224-232. doi:10.1123/IJSC.2017-0029

Sharpe, S., Kunkel, T., Scott, O., \& Beaton, A. (2017). Managing digital content for a professional sport team: An interview with Bill Yole, social media coordinator and webmaster of the ACT brumbies super rugby franchise. International Journal of Sport Communication, 10(3), 318-324. doi:10.1123/ijsc.2017-0060

Sky Sport New Zealand [@skysportnz]. (2020, March 22). Great message from Tabai Matson! Happy hand washing [Tweet; video content]. Twitter. Retrieved from https:// twitter.com/skysportnz/status/1241573076325761025

Smith, L.R., \& Sanderson, J. (2015). I'm going to Instagram it! An analysis of athlete self-presentation on Instagram. Journal of Broadcasting \& Electronic Media, 59(2), 342-358. doi:10.1080/08838151.2015.1029125

Stavros, C., Meng, M.D., Westberg, K., \& Farrelly, F. (2014). Understanding fan motivation for interacting on social media. Sport Management Review, 17(4), 455-469. doi:10. 1016/j.smr.2013.11.004

Williams, J., \& Chinn, S.J. (2010). Meeting relationship-marketing goals through social media: A conceptual model for sport marketers. International Journal of Sport Communication, 3(4), 422-437. doi:10.1123/ijsc.3.4.422

Williams, J., Chinn, S.J., \& Suleiman, J. (2014). The value of Twitter for sports fans. Journal of Direct, Data and Digital Marketing Practice, 16(1), 36-50. doi:10.1057/dddmp. 2014.36 